\title{
Study on drug utilization pattern and cost analysis among the psychiatric patients treated with various benzodiazepine derivatives
}

\author{
Dhivya Govindasamy ${ }^{1 *}$, Gandhibabu Ramanathan², Talari Venkata Siva Prasad ${ }^{1}$, \\ Gopalakrishnan Ganesan ${ }^{1}$
}

${ }^{1}$ Department of Pharmacy, ${ }^{2}$ Department of Psychiatry, Annamalai University, Annamalai Nagar, Tamil Nadu, India

Received: 24 April 2020

Revised: 12 May 2020

Accepted: 13 May 2020

*Correspondence:

Dr. Dhivya Govindasamy,

Email: dhivyagovindasamy4@gmail.com

Copyright: ( $)$ the author(s), publisher and licensee Medip Academy. This is an open-access article distributed under the terms of the Creative Commons Attribution Non-Commercial License, which permits unrestricted non-commercial use, distribution, and reproduction in any medium, provided the original work is properly cited.

\begin{abstract}
Background: The objective of the study was to assess drug utilization pattern and cost analysis among the psychiatric patients treated with various benzodiazepine derivatives.

Methods: This observational study was conducted in department of psychiatric, RMMCH, Annamalai University. The study period was 6 months (November 2018 to April 2019). A total of 50 psychiatric patients were included.

Results: A total 50 patients among them 64\% (32) males and 36\% (18) female, were included in the study. Most of the patient were between the age groups of 18-29 years (30\%). The most common clinical condition treated with benzodiazepines were alcohol dependence syndrome/alcohol withdrawal syndrome/ alcohol related psychotic disorder (34\%). The majority of patients were prescribed with clonazepam $(66.67 \%)$. The defined daily dose (DDD) per 100 bed days of benzodiazepines were found to be 0.89 . In this study the comparison of cost analysis for the drug used and it was found that lorazepam (122\%) are most expensive followed by chlordiazepoxide (93.3\%) and clonazepam (78.57\%). The cheapest drug was nitrazepam (36.84\%).

Conclusions: The majority of the patient admitted in the psychiatric department were suffering from Alcohol depending syndrome/alcohol withdrawal syndrome. The most commonly prescribed benzodiazepine was clonazepam followed by lorazepam and least prescribed diazepam and nitrazepam based on defined daily dose concept.
\end{abstract}

Keywords: Drug utilization, Benzodiazepine, DDD, Cost analysis

\section{INTRODUCTION}

Benzodiazepine are class of medications that work in the central nervous system and are used for a variety of medical conditions, such as anxiety, seizures, and for alcohol withdrawal. Benzodiazepines appear to work by blocking excessive activity of nerves in the brain and other areas in the central nervous system. As a class, benzodiazepines are similar in how they work in the brain but have different potencies and durations of actions. Because of this, some benzodiazepines work better than others in the treatment of particular conditions. Common examples of benzodiazepines include diazepam and
Lorazepam. All benzodiazepines are listed as DEA schedule IV-controlled substances. ${ }^{1}$

Drug utilization defined by the WHO as the marketing, distribution, prescription, and use of drugs in a society, with special emphasis on the resulting medical, social and economic consequences. A drug utilization study is therefore a study designed to describe-quantitatively and qualitatively the population of users of a given drug (or class of drug) and or the conditions of use (for example, indications, duration of treatment, dosage, previous or associated treatments and compliance). ${ }^{2}$ 
The anatomical therapeutic chemical/ defined daily dose (ATC/DDD) system was recommended by WHO as the international standard for drug utilization studies. The main purpose of the ATC/DDD system is as a tool for presenting drug utilization statistics with the aim of improving drug use. This is the purpose for which the system was developed and it is with this purpose in mind that all decision about ATC/DDD classification are made. consequently, using the system for other purposes can be inappropriate.

\section{Anatomical and therapeutic classification}

ATC classification system is an international classification system of drug, used as a tool for performing comparative drug utilization studies.

\section{Defined daily dose}

The DDD is the assumed average maintenance dose per day for a drug used for its main indication in adult. It is defined globally for each medicine by the WHO collaborating centre for drug statistics. The DDD is a unit of measurement and does not necessarily reflect the recommended or prescribed daily dose. Therapeutic doses for individual patients and patient groups will often differ from the DDD as they will be based on individual characteristics (such as age, weight, ethnic differences, type and severity of disease) and pharmacokinetic considerations. $^{3}$

Pharmacoeconomics is defined as 'a branch of health economics which particularly focuses upon the costs and benefits of drug therapy'. Most clinicians have little exposure to health economics, as it is a relatively new discipline in the health sciences. Pharmaco-economical research is primarily driven by the principle that financial resources are limited and that organizational needs generally exceed available resources.

A 'comparator' is essential for a pharmacoeconomic trial. Such trials should compare the new drug/procedure with an older drug or existing intervention. The comparator can either be the 'gold standard' drug/intervention in that condition or the most commonly used drug, dosage or procedure. The choice of the comparator can lead to considerable bias, e.g. use of an older generation drug (in spite of the availability of better options) or a suboptimal dose as a comparator. ${ }^{4}$

The objective of the study was to improve rational use of benzodiazepine derivatives in different psychiatric condition and make patient reduce economic burden, thus we conduct the study on drug utilization pattern and cost analysis among the psychiatric patients treated with various benzodiazepine derivatives.

\section{METHODS}

This was an observational study conducted at department of psychiatric, Rajah Muthiah Medical College and Hospital, Annamalai University, Annamalai Nagar, Tamil Nadu, from the period of November 2018 to April 2019, approved by the Institutional Ethics Committee.

\section{Inclusion criteria}

Patients age above 18 years, both genders, admitted in psychiatric ward, and prescribed with benzodiazepines were included in this study.

\section{Exclusion criteria}

Patients who are not willing to participate, not providing informed consent form, patient who were pregnant, lactating and unconscious.

\section{Study method}

Benzodiazepine were classified using ATC system (WHO-ATC,2019) and consumption of benzodiazepine measured by DDD per 100 bed-days. ${ }^{3}$

\section{DDD per 100 bed days}

The DDDs per 100 bed days may be applied when drug use by inpatient is considered. The definition of a bed day may differ between hospitals or countries. A common definition is a bed day is a day during which a person is confined to a bed and in which the patient stays overnight in a hospital. Day case are sometimes included as one bed day and sometime excluded. ${ }^{5}$

DDD (for 100 bed-days) $=$

Total dose in mg during study period X100

DDD of the drug X study duration (days)X bed strength $\mathrm{X}$ average bed occupancy rate

DDD $=\frac{\text { No of items issued } \mathrm{X} \text { amount of drug per item }}{\text { WHO DDD }}$

Occupancy index $=\frac{\text { Total inpatient days X } 100}{\text { Available beds X study period }}$

\section{Price variation}

Comparing two or more medicine of equal therapeutic effectiveness and safety to find out which one is the cheapest. It can be used to compare different brand of same drug. ${ }^{6}$

Price of most expensive brand - price of least expensive brand Price of least expensive brand 


\section{Statistical analysis}

Data was entered and analyzed with microsoft excel 2007. Descriptive statistics were used to analyze the results. Percentage and averages of the variable were also calculated to compare the data with other findings.

\section{RESULTS}

Total of 50 patients were divided into five age trends 18 29 years $(30 \%), 30-39$ years $(28 \%), 40-49$ years $(26 \%)$, $50-59$ years $(10 \%)$ and $>60$ years $(6 \%)$. In our study most of the patient come under 18-29 years (30\%) were given in Table 1.

Table 1: Age wise distribution $(\mathrm{n}=50)$.

\begin{tabular}{|llll|}
\hline S. no & $\begin{array}{l}\text { Age group } \\
\text { (in years) }\end{array}$ & No. of patients & $\%$ \\
\hline 1. & $18-29$ & 15 & 30 \\
\hline 2. & $30-39$ & 14 & 28 \\
\hline 3. & $40-49$ & 13 & 26 \\
\hline 4. & $50-59$ & 5 & 10 \\
\hline 5. & $>60$ & 3 & 6 \\
\hline
\end{tabular}

Among 50 prescription, the majority of patients were prescribed clonazepam $32(66.67 \%)$ followed by lorazepam 10 (20.83\%), diazepam 3 (6.25\%) and nitrazepam $3(6.25 \%)$ (Table 2 ).

Table 2: Prescribing pattern of benzodiazepines (monotherapy $n=48$ ).

\begin{tabular}{|llll|}
\hline S. no & Benzodiazepine & No. of patients & $\%$ \\
\hline 1. & Clonazepam & 32 & 66.67 \\
\hline 2. & Lorazepam & 10 & 20.83 \\
\hline 3. & Diazepam & 3 & 6.25 \\
\hline 4. & Nitrazepam & 3 & 6.25 \\
\hline
\end{tabular}

The most common treatment is monotherapy $96 \%$ of all the prescription and $4 \%$ of prescription were dual therapy. Clonazepam $(66.67 \%)$ is most commonly prescribed drug as monotherapy followed by lorazepam $(20.83 \%)$ and diazepam was the least used drug $(6.25 \%)$. The dual therapy $4 \%$ was given for the psychiatry disorder treatment among which dual therapy (escitolopram $5 \mathrm{mg}$ and clonazepam $0.5 \mathrm{mg}$ ) was given in 2 patients (Table 3 ).

Table 3: Prescribing pattern of benzodiazepine dual therapy $(n=2)$.

\begin{tabular}{|lll|}
\hline Combination & No. of patients & $\%$ \\
\hline $\begin{array}{l}\text { Escitolopram } 5 \text { mg and } \\
\text { clonazepam } \mathbf{0 . 5} \mathbf{~ m g}\end{array}$ & 2 & 100 \\
\hline
\end{tabular}

During the study period, the most common clinical condition of patients treated with benzodiazepine were alcohol related psychotic disorder 17 (34\%) followed by bipolar affective disorder mania 12 (24\%), depressive disorder 7 (14\%) and acute transient psychotic disorder 5 $(10 \%)$ and schizophrenia $5(10 \%)$ were shown in (Table 4).

Table 4: Distribution pattern of patient according to clinical conditions $(n=50)$.

\begin{tabular}{|llll|}
\hline S. no & $\begin{array}{l}\text { Clinical conditions } \\
\text { 1. }\end{array}$ & $\begin{array}{l}\text { No. of } \\
\text { patients }\end{array}$ & \% \\
\hline & $\begin{array}{l}\text { Alcohol dependence } \\
\text { syndrome/alcohol } \\
\text { withdrawal syndrome/ } \\
\text { alcohol related } \\
\text { psychotic disorder }\end{array}$ & 17 & 34 \\
\hline 2. & $\begin{array}{l}\text { Bipolar affective } \\
\text { disorder mania }\end{array}$ & 12 & 24 \\
\hline 3. & Depressive disorder & 7 & 14 \\
\hline 4. & Schizophrenia & 5 & 10 \\
\hline 5. & $\begin{array}{l}\text { Acute and transient } \\
\text { psychotic disorder }\end{array}$ & 5 & 10 \\
\hline 6. & Anxiety disorder & 2 & 4 \\
\hline 7. & $\begin{array}{l}\text { Mental and behavioral } \\
\text { disorder due to alcohol }\end{array}$ & 2 & 4 \\
\hline
\end{tabular}

In our study usage of benzodiazepine were calculated in terms of DDD per 100 bed-days and benzodiazepines were 0.89 . Nitrazepam 0.578 followed by diazepam 0.25 and the least is clonazepam 0.035 and lorazepam 0.028 . The ATC code and the DDD per 100 bed-days of the prescribed benzodiazepines were shown in (Table 5).

Table 5: The ATC codes and DDD per 100 bed-days of benzodiazepines prescribed.

\begin{tabular}{|llll|}
\hline Benzodiazepine & $\begin{array}{l}\text { ATC } \\
\text { code }\end{array}$ & $\begin{array}{l}\text { WHO } \\
\text { DDD } \\
\text { (mg) }\end{array}$ & $\begin{array}{l}\text { DDD per } \\
\text { 100 bed } \\
\text { days }\end{array}$ \\
\hline Lorazepam & No5ba06 & 2.5 & 0.028 \\
\hline Clonazepam & No3ae01 & 8 & 0.035 \\
\hline Diazepam & No5ba01 & 10 & 0.25 \\
\hline Nitrazepam & No5cd02 & 5 & 0.578 \\
\hline
\end{tabular}

Note: ATC: anatomical and therapeutic classification system; DDD: defined daily dose.

Table 6: Cost per defined daily dose (DDD).

\begin{tabular}{|lllll|}
\hline \multirow{2}{*}{ Drugs } & \multicolumn{2}{c}{ Cost per item } & \multirow{2}{*}{ CD } & SC $(\%)$ \\
\hline Lorazepam & HC & LC & & \\
\hline Clonazepam & 2.00 & 0.9 & 1.1 & 122 \\
\hline Diazepam & 5.32 & 3.16 & 2.16 & 68.35 \\
\hline Nitrazepam & 1.5 & 0.84 & 0.66 & 78.57 \\
\hline Chlordiazepoxide & 1.3 & 0.95 & 0.35 & 36.84 \\
\hline
\end{tabular}

HC: high cost; LC: low cost; CD: cost difference; SC: saving cost.

The comparison of cost analysis for the drug used and it was found that lorazepam (122\%) are most expensive 
followed by chlordiazepoxide (93.3\%) and clonazepam (78.57\%). The cheapest drug nitrazepam (36.84\%) (Table $6)$.

\section{DISCUSSION}

The study was conducted with 50 psychiatry patients in which $32(64 \%)$ of them were male and $18(36 \%)$ of them female. The patient was selected upon the fulfillment of inclusion and exclusion criteria. our study was observational study taken place in tertiary care teaching hospital. To study the drug utilization pattern of benzodiazepine derivative by using DDD/ATC concept.

In our study the maximum number of patient were in the age group of $18-29$ years $(30 \%)$ age where in uday venkat mateti pramitha prabhakaran, Sanal et al concluded that higher number of psychiatry patients were seen between age group of 30-39 years. $^{7}$ The proportion of male patients admitted to the psychiatric department was more than female patients similar finding were reported by Jayaprakash. ${ }^{8}$ Patients with no family history of mental illness were found more, compared with history of mental illness in family.

Out of 50 prescription, the majority of the patients were prescribed clonazepam (66.67\%) in psychiatric department. Similar results were reported by Bernard et al. ${ }^{9}$ A contradictory result was shown in a study carried out by Ramadan et al and it was found that alprazolam (34.6\%) was the most commonly prescribed drug. ${ }^{10}$ The most commonly prescribed benzodiazepine for treatment of alcohol withdrawal syndrome/alcohol dependence syndrome/alcohol related psychotic disorder (34\%). The similar finding was observed in the study conducted by Mateti et al and Sachdeva et al and Lejoyeux et al also shows that benzodiazepine was the drug of choice for the treatment of alcohol withdrawal syndrome. .,11,12 $^{2}$

In our study usage of benzodiazepine were calculated in terms of DDD per 100 bed-days for benzodiazepines were 0.89 . The DDD of benzodiazepine were higher than the results shown by Mateti et al found DDD per 100 beddays for benzodiazepine were $0.98 .^{7}$ The DDD of clonazepam were higher than the result shown by Thakkar et al. ${ }^{13}$ By comparing this study, maximum price variation of lorazepam is found that saving cost $122 \%$ and in the high cost brand INR 2.0 and the lowest cost brand INR 0.9 . which is lower than the study conducted by Stimac et al. ${ }^{14}$ They have compared benzodiazepine derivative drugs manufactured by different pharmaceutical companies in the same strength and dosage form. The results of their study showed the price variation in the high cost and low-cost brand.

\section{CONCLUSION}

In conclusion, this study has shown the utilization of benzodiazepine in psychiatric patient. The most commonly prescribed benzodiazepine for treatment of alcohol depending syndrome/alcohol withdrawal syndrome was clonazepam. In this study help to optimize the drug therapy, improve the quality of care and reduce the negative outcome. It is concluded that cheaper drugs can be prescribed to patients reducing the healtheconomic burden on psychiatric patients.

\section{ACKNOWLEDGEMENTS}

I would like to thank Rajah Muthiah Medical College and Hospital for allowing to conduct the study and then I would like to thank my parents and friends.

Funding: No funding sources

Conflict of interest: None declared

Ethical approval: The study was approved by the Institutional Human Ethics Committee (IHEC/0393/2018)

\section{REFERENCES}

1. Anderson LA. Pharm D-Benzodiazepine: overview and use. Available at: https://www.drugs.com. Accessed on 21 January 2019.

2. Truter I. A Review of Drug Utilization Studies and Methodologies. Jordan J Pharmaceutical Sci. 2008;1(2):91-104.

3. ATC Guidelines. Available at: https://www. whocc.no/atc_ddd_index/. Accessed on 21 January 2019.

4. Ahuja J, Gupta M, Gupta AK, Kohli K. Pharmacoeconomics. National Med J India. 2004;17(2):80-3.

5. Available at: https://www.who.int/medicines/regul ation/medicinesafety/toolkit-indicators/en/index1. htmIDDD indicators. Accessed on 21 January 2019.

6. Jainam SV, Kalyani PN, Shrikalp DS. Pharmacoeconomic Evaluation, Cost Minimization Analysis of Anti-Diabetic Therapy in Gujarat. Int $\mathbf{J}$ Med Res Health Sci. 2016;5(3):34-43.

7. Mateti UV, Prabhakaran P, Sanal TS. Utilization Patterns of Benzodiazepines in Psychiatric Patients in a Tertiary Care Teaching Hospital. Asia Pac Clin Transl Nerv Syst Dis. 2018;1(4):196-201.

8. Jayaprakash K. Study of Utilization Pattern of Benzodiazepine's at a Private Corporate Hospital. Int J Res Pharmaceutical Nanosci. 2014;3(4):357-61.

9. Michele M, Heliyon BT. Pattern of Benzodiazepines use in Primary care Adults with Anxiety Disorders. Available at: http://creativecommons.org/licenses/ by-nc-nd/4.0/. Accessed on 21 January 2019.

10. Ramadan WH. Prescription Patterns of Benzodiazepines in the Lebanese Adult Population: A Cross-Sectional Study. Neuropsychiatr Dis Treat. 2016;(12):2299-305.

11. Sachdeva A, Choudhary M, Chandra M. Alcohol Withdrawal Syndrome: Benzodiazepines and Beyond. J Clin Diagnostic Res. 2015;9(9):1-7.

12. Lejoyeux M. Benzodiazepine Treatment for AlcoholDependent Patients Medical Council on Alcoholism. Alcohol Alcohol. 1998;33(6):563-75. 
13. Thakkar KB, Jain MM, Khobragade AA. A Drug Utilization Study Psychotropic Drug Prescribed in the Psychiatry outpatient Department of a Tertiary Care Hospital. J Clin Diagnostic Res. 2013;7(12);2759-64.

14. Stimac D, Culig J. outpatient Utilization of psychopharmaceuticals in the city of Zagreb 20012006. Psychiatr Danub. 2009;21(1):56-64.
Cite this article as: Govindasamy D, Ramanathan G, Prasad TVS, Ganesan G. Study on drug utilization pattern and cost analysis among the psychiatric patients treated with various benzodiazepine derivatives. Int J Basic Clin Pharmacol 2020;9:975-9. 